\title{
Role of Catalytic and Lysine-binding Sites in Plasmin-induced Neutrophil Adherence to Endothelium
}

\author{
S. K. Lo, T. J. Ryan, N. Gilboa, L. Lai, and A. B. Malik \\ Departments of Physiology and Pediatrics, The Albany Medical College of Union University, Albany, New York 12208; and Wadsworth \\ Center for Laboratories and Research, New York State Department Of Health, Albany, New York 12201
}

\begin{abstract}
Plasmin resulted in increased neutrophil adherence to cultured ovine pulmonary artery endothelial cell monolayers in a concentration-dependent manner $\left(10^{-12}-10^{-7} \mathrm{M}\right)$. The adherence response increased fivefold above baseline within 60 min after addition of plasmin $\left(10^{-8} \mathrm{M}\right)$ and the response persisted up to $30 \mathrm{~min}$ after removal of plasmin. The neutrophil adherence was mediated by the action of plasmin on neutrophils rather than endothelial cells. The response was the result of an increase in functional activity of CD18 neutrophil cell surface adhesive glycoprotein. Neutrophil adherence was inhibited by pretreatment of neutrophils with MAbs IB4 and 60.3 targeted against the $\beta$ chain of the CD18, whereas control isotypic MAb 60.5 against HLA class I antigen had no effect. The plasmin catalytic site was not involved in the response. Lys-plasminogen had reduced adherence-promoting activity relative to plasmin, whereas glu-plasminogen had no effect. Elastase-derived plasminogen fragments corresponding to kringle $1+2+3$ and kringle 4 (both of which contained the lysine-binding sites) possessed neutrophil adherence-promoting activities similar to plasmin, whereas miniplasminogen (which contains the catalytic site but no lysine-binding sites) had minimal effect, indicating the involvement of lysine-binding sites in the response. Blocking lysine-bînding sites of plasmin and elastase-derived plasminogen fragments with tranexamic acid ( IC $_{50}$ of $5 \mathrm{mM}$ ) inhibited neutrophil adherence. A monospecific polyclonal antibody against the lysine-binding sites also reduced the neutrophil adherence-promoting activity of plasmin. The results indicate that plasmin induces neutrophil adherence to the endothelium and that the effect is mediated by lysine-binding sites on plasmin.
\end{abstract}

\section{Introduction}

Plasmin, a serine protease, has a well-defined role in fibrinolysis (1-3). Cleavage of the $\operatorname{Arg}(560)-\mathrm{Val}(561)$ bond of plasminogen results in the generation of plasmin, a reaction catalyzed by urokinase and tissue plasminogen activator (1). Plasmin consists of two chains: a light $\left(M_{\mathrm{r}} 25,000\right)$ and a heavy $\left(M_{\mathrm{r}}\right.$

Dr. S. K. Lo's present address is Laboratory of Cellular Physiology and Immunology, The Rockefeller University, 1230 York Avenue, New York, NY 10021. Address reprint requests to Dr. A. B. Malik, Department of Physiology, Albany Medical College, 47 New Scotland Avenue, Albany, NY 12208.

Received for publication 21 November 1988 and in revised form 9 May 1989.

J. Clin. Invest.

(C) The American Society for Clinical Investigation, Inc.

0021-9738/89/09/0793/09 \$2.00

Volume 84, September 1989, 793-801
$48,000-63,000)$ chain (2). The catalytic site resides in the light chain (2). The heavy chain consists of five homologous domains called "kringles," the first four of which contain the lysine-binding sites (LBS) ${ }^{1}(2,4)$. The native molecule, gluplasminogen, has one high-affinity LBS and five low-affinity LBS, whereas the modified plasminogen, lys-plasminogen, has one high-, one intermediate-, and four low-affinity LBS (5-7). The exact number of LBS on plasmin is presently unknown. The LBS on plasmin and plasminogen mediate binding to fibrin (8) and to cell surfaces (9-14), thereby enhancing the activation rate of plasminogen $(10,12)$. The inactivation of plasmin by plasma protease inhibitor ( $\alpha_{2}$-plasmin inhibitor) is also a LBS-dependent process (2).

Alpha $_{2}$-antiplasmin rapidly inhibits the plasmin generated in the circulation; however, the inhibitory capacity of $\alpha_{2}$-antiplasmin may be exceeded during generation of plasmin in pathological conditions such as disseminated intravascular coagulation, liver disease, fibrinolytic activator therapy, and pulmonary microembolism (1). Circulating plasmin may participate in the inflammatory response by an action on bloodformed elements and endothelial cells. It is known that plasminogen binds avidly to endothelial cells and platelets in a specific, reversible, and saturable manner $(10,11)$ by receptors that appear to be distinct from thrombin receptors (9). Plasmin $(>1 \mathrm{U} / \mathrm{ml})$ induces platelet aggregation, protein phosphorylation, calcium mobilization, and activation of phospholipase $C$ and protein kinase $C$ in platelets $(15,16)$. In addition, the generation of plasmin after intravascular fibrin entrapment may contribute to the vascular sequestration of neutrophils $(17,18)$.

An adhesive interaction between neutrophils and vascular endothelium is a key event in acute inflammation. Inflammatory mediators (e.g., thrombin, leukotriene $\mathrm{B}_{4}\left[\mathrm{LTB}_{4}\right]$, tumor necrosis factor [TNF], IL 1, C5a) modulate neutrophil adhesiveness (17-25), which, in large part, is mediated by the cell surface glycoprotein (CD18) on neutrophils $(22,26)$. This conclusion is based on the findings that neutrophils obtained from patients with genetic CD18 deficiency do not adhere to endothelium when stimulated (26) and that MAbs directed against CD18 prevent neutrophil adhesion to the endothelium (26). Because fibrinolysis and inflammation often occur simultaneously (16), in this study, we have examined whether this key fibrinolytic enzyme possesses a neutrophil adhesion-promoting activity. We also examined the characteristics of the response (i.e., roles of neutrophil versus endothelium and of

1. Abbreviations used in this paper: $\alpha_{2}$-PI, alpha ${ }_{2}$-plasmin inhibitor; DFP, diisopropylfluorophosphate; HUVEC, human umbilical vein endothelial cells; HOF, human ocular fibroblast culture; LBS, lysinebinding sites; SPAE, sheep pulmnary endothelial cells; TX, tranexamic acid. 
CD18 in mediating the adherence) and the specific molecular domains on plasmin responsible for neutrophil adhesion.

\section{Methods}

Plasmin and plasminogen preparations. Porcine plasmin, purchased from Sigma Chemical Co. (St. Louis, MO), was dissolved at concentration of $10^{-6} \mathrm{M}$ in $10 \mathrm{mM}$ Tris, $150 \mathrm{mM} \mathrm{NaCl}$ at $\mathrm{pH} 7.4$, and stored at $-70^{\circ} \mathrm{C}$. The catalytic activity of plasmin was determined using H-D-Nle-HHT-Lys-pNa.2AcOH (Spectrozyme-P1) in a plasmin-specific chromogenic substrate assay (American Diagnostica, Greenwich, CT). Detailed methods for the catalytic assay have been previously described (27). In some cases, the effects of human plasmin were examined. Human plasmin and native glu-plasminogen were prepared as described previously (28). Lys-plasminogen was supplied by Dr. F. Toulemonde, Choay Laboratories, Paris, France.

Inhibition of catalytic activity of plasmin. The catalytic site of plasmin was inactivated with diisopropylfluorophosphate (DFP), Trasylol, and $\alpha_{2}$-plasmin inhibitor $\left(\alpha_{2}\right.$-PI) as described below:

(a) DFP (0.2 $\mathrm{M}$ in 2-propanol) was added to plasmin $\left(10^{-6} \mathrm{M}\right)$ at a DFP/plasmin ratio of 5:95 (vol/vol). After $5 \mathrm{~h}$, at $4^{\circ} \mathrm{C}$, the DFP-plasmin solution was dialyzed extensively against $0.05 \mathrm{M}$ Tris buffer $(\mathrm{pH}$ 7.4). DFP-plasmin was aliquoted and frozen at $-70^{\circ} \mathrm{C}$.

(b) Trasylol (Sigma Chemical Co.) was added to plasmin using 10:1 (U/U) ratio for $10 \mathrm{~min}$ at $20^{\circ} \mathrm{C}$. The Trasylol-treated plasmin was subjected to extensive dialysis. Both DFP- and Trasylol-inhibited plas$\min$ had $<0.1 \%$ residual plasmin activity.

(c) $\alpha_{2}$-PI (a gift of Dr. Peter C. Harpel, The New York HospitalCornell Medical Center, NY) was mixed with $1 \mathrm{ml}$ plasmin $\left(10^{-7} \mathrm{M}\right)$ at $\alpha_{2}$-PI concentration of $1.1 \mathrm{mg} / \mathrm{ml}$ (inhibitor/plasmin molar ratio $=5: 1$ ). The reaction was allowed to proceed for $10 \mathrm{~min}$ at $20^{\circ} \mathrm{C}$. The $\alpha_{2}$-PI complexed with plasmin was aliquoted and stored at $-70^{\circ} \mathrm{C}$. Residual activity of plasmin was $<0.1 \%$.

Neutrophil adhesion site and plasminogen antibodies. MAb IB4 was provided by Dr. S. D. Wright, The Rockefeller University, NY. MAb IB4 recognizes epitopes of the $\beta$ chain of the CD18 heterodimer complex (consisting of CR3, LFA-1, and p150,95, the cell-surface adhesive glycoproteins present on peripheral leukocytes [26, 29, 30]). MAb 60.3 and 60.5 were gifts of Dr. J. Harlan and Dr. P. Beattie, University of Washington, Seattle, WA. MAb 60.3 also recognizes the $\beta$ chain of CD18 (21) and the control isotypic MAb 60.5 is targeted against the HLA class I antigen on peripheral leukocytes (21). MAb 60.3 and 60.5 were shown to react with sheep neutrophils by indirect immunofluorescence microscopy and the cross-reactivity of murine MAb IB4 towards sheep leukocytes was demonstrated using a FACS (Becton-Dickinson \& Co., Oxnard, CA).

FACS analysis of neutrophil CD18 expression. Expression of CD18 heterodimer complex on neutrophils was analyzed using FACS. Sheep neutrophils $\left(10^{6}\right.$ cells $\left./ \mathrm{ml}\right)$ were incubated with plasmin $\left(10^{-8} \mathrm{M}\right)$ for 60 min at $37^{\circ} \mathrm{C}$, plasmin was then washed off, followed by incubating neutrophils with FITC-conjugated IB4 at a final concentration of 10 $\mu \mathrm{g} / \mathrm{ml}$ at $4^{\circ} \mathrm{C}$ for $10 \mathrm{~min}$. The cells were washed free of the unbound antibody and resuspended in ice-cold phosphate buffer. Fluorescence was analyzed with a FACScan (Becton-Dickinson \& Co.). Fluorescent intensity of 5,000 cells was determined and was expressed as mean channel of fluorescence.

Preparation of elastase-derived plasminogen fragments. Human lys-plasminogen was treated with porcine pancreatic elastase (Worthington Diagnostic Systems, Freehold, NJ) in $0.3 \mathrm{M}$ ammonium bicarbonate buffer containing soybean trypsin inhibitor (4). The resulting fragments were separated by chromatography on L-lysine-coupled Sepharose (Pharmacia Fine Chemicals, Piscataway, NJ) and gel filtered on Sephadex G-75 (4). The fragments were characterized by amino acid analysis, $\mathrm{NH}_{2}$-terminal analysis, and SDS-PAGE. Amino acid analysis was consistent with two molecular weight variants $\left(M_{\mathrm{r}}\right.$ $=40,000$ and 42,000; residues tyr-79 to val-337, tyr-79 to val-353) for the kringle $1+2+3$. Kringle 4 had $M_{\mathrm{r}}$ of 7,000-12,000 (val-354 to ala-439). Kringle $5+$ light chain possessed $M_{\mathrm{r}}$ of $35,000-39,000$ (val-442 to asn-790 and leu-449 to asn-790). The plasmin contamination in the preparations of lys-plasminogen and the plasminogen fragments was $<0.1 \%$.

Preparation of monospecific polyclonal antibody. Monospecific polyclonal antibody against the LBS on kringle $1+2+3$ was prepared by the method of Miles and Plow (31). The antibodies eluted from plasminogen-coupled Sepharose by $\epsilon$-aminocaproic acid were further purified by chromatography on protein A-coupled Sepharose.

Neutrophil isolation and labeling. The isolation of sheep neutrophils involved two steps (32): hemolysis of erythrocytes in leukocyterich fraction and separation of neutrophils from other cells by centrifugation over a continuous Percoll gradient. The purity of neutrophils was $>95 \%$, as indicated by Wright-Giemsa stain. Viability of $>98 \%$ of the isolated neutrophils was demonstrated using trypan blue exclusion. Freshly isolated neutrophils were suspended in Hanks' solution containing $25 \mathrm{mM}$ Hepes, $1 \mathrm{mg} / \mathrm{ml}$ BSA and $20 \mathrm{mM}$ EDTA for 51-Chromium $\left({ }^{51} \mathrm{Cr}\right.$, New England Nuclear, Boston, MA) labeling. ${ }^{51} \mathrm{Cr}$ (0.2-0.5 $\mu \mathrm{Ci})$ per $10^{6}$ neutrophils was added to the neutrophil suspension. The neutrophils and ${ }^{51} \mathrm{Cr}$ were incubated for $30 \mathrm{~min}$ at $37^{\circ} \mathrm{C}$. Free ${ }^{51} \mathrm{Cr}$ was removed by washing with Hanks' solution plus $20 \mathrm{mM}$ EDTA and the pelleted neutrophils from the last centrifugation $(450 \mathrm{~g}$, $5 \mathrm{~min}, 4^{\circ} \mathrm{C}$ ) were resuspended in an appropriate volume to yield a cell concentration of $2 \times 10^{6}$ cells $/ \mathrm{ml}$. After labeling, $>98 \%$ of the neutrophils were found to exclude trypan blue and these cells showed minimal basal adherence ( $<5 \%$ adherence) to the endothelium.

For isolation of human neutrophils, whole blood was collected from healthy donors by venipuncture into acid-citrate-dextrose and centrifuged to obtain a buffy coat. The buffy coat was separated into neutrophil-rich fraction by dextran sedimentation, followed by FicollHypaque gradient centrifugation, and hypotonic lysis of erythrocytes. The washed neutrophils were suspended in HBSS without ions, with $25 \mathrm{mM}$ Hepes, $20 \mathrm{mM}$ EDTA, and $0.1 \% \mathrm{BSA}$ and the pH was adjusted to 7.4. The purity of neutrophils was over $98 \%$ and their viability was $>99 \%$. The cells were labeled with ${ }^{51} \mathrm{Cr}$ as described above.

Endothelial cell culture. Sheep pulmonary artery endothelial cells (SPAE) were obtained as previously described (29). The cells were shown to be endothelial in origin by the presence of Factor VIII-related antigen, angiotensin converting enzyme activity, acylated low-density lipoprotein binding, and exhibited typical cobblestone morphology. Endothelial cells were plated at $10^{5} \mathrm{cells} / \mathrm{ml}$ and grown to confluence while being maintained on DME plus $10 \%$ FCS. Multiple passage (P8-P18) of SPAE were used. Endothelial cell monolayers were used within $3 \mathrm{~d}$ of seeding.

Human umbilical vein endothelial cells (HUVEC) cells were prepared by collagenase treatment. HUVEC were maintained in RPMI 1640 with $20 \%$ fetal bovine serum, $6.5 \mu \mathrm{g} / \mathrm{ml}$ retinal-derived growth factor, and $75 \mu \mathrm{g} / \mathrm{ml}$ heparin. Cells were plated in 16-mm diameter wells in 24-well plates at $10^{5}$ cells/well. Confluent monolayers were formed within $3 \mathrm{~d}$ of seeding when the study was carried out.

Neutrophil adherence assay. The culture medium was aspirated and endothelial cells were washed with DME. To each well, $100 \mu \mathrm{l}$ of ${ }^{51} \mathrm{Cr}$-labeled sheep neutrophils were added, followed by the stimulant $(100-\mu 1$ volume). The wells were gently agitated and were incubated at $37^{\circ} \mathrm{C}$ in a $\mathrm{CO}_{2}$ incubator. At the end of the incubation period, the supernatant medium and the nonadherent neutrophils were aspirated and each well was washed three times with PBS. Endothelial cell monolayers were intact as assessed with phase contrast microscopy. Endothelial cells and adherent neutrophils were lysed with $1 \mathrm{M} \mathrm{NaOH}$ overnight. Radioactivity of the lysate was measured by a gamma counter (Amersham Corp., Arlington Heights, IL). The background (counting vial without cells) activity was subtracted. Neutrophil adherence (expressed in a percentage) was calculated as the remaining ${ }^{51} \mathrm{Cr}$ activity divided by the total added ${ }^{51} \mathrm{Cr}$ activity. Phase contrast microscopy confirmed neutrophil adherence to the endothelial cells.

Human ocular fibroblast culture. Human ocular fibroblast culture (HOF) were prepared and maintained in DME with $20 \%$ fetal bovine serum (33). Then cells were plated in 16-mm-diam wells in 24-well plates at $2 \times 10^{6}$ cells/well. Confluent layers were formed after $24 \mathrm{~h}$ 
incubation. Purified and ${ }^{51} \mathrm{Cr}$-radiolabeled human neutrophils (2 $\left.\times 10^{6}\right)$ in DME suspension were layered on the $16-\mathrm{mm}$ plastic well (24-multiwell; Corning Medical, Corning, NY) containing confluent HOF $2 \times 10^{5}$ cells/well. Human plasmin $\left(10^{-8} \mathrm{M}\right.$ in $\left.0.1 \mathrm{ml}\right)$ or $0.1 \mathrm{ml}$ DME were added each well. The total assay medium contained $1 \mathrm{ml}$ fluid volume in each well. With the exception of the volume per well, the assay procedures were identical to the conditions used with endothelial cells.

Statistics. Analysis of variance followed by a multiple-range test for comparisons within experimental groups were used to compare significance of treatment groups. $P<0.05$ was accepted as significant. Results are shown as mean \pm SEM.

\section{Results}

Plasmin resulted in neutrophil adherence to cultured pulmonary artery endothelial cell monolayers. Neutrophil adherence did not increase over the basal adherence after $10 \mathrm{~min}$ of plasmin exposure, whereas, by $30 \mathrm{~min}$, the response increased threefold $(P<0.05)$, with the maximal increase of fivefold attained at $60 \mathrm{~min}$ (Fig. 1). All subsequent experiments were made with the 60 min plasmin incubation time. Neutrophil adherence to endothelial monolayers also increased in a concentration-dependent manner (Fig. 2). No effect was noted at plasmin concentration $<10^{-11} \mathrm{M}$, whereas an increase was evident at $10^{-10} \mathrm{M}(P<0.05)$, and maximal increases occurred at $10^{-8}$ and $10^{-7} \mathrm{M}$ plasmin. A plasmin concentration of $10^{-8}$ $M$ was used in all subsequent experiments.

Because plasmin is a serine protease with a trypsin-like activity and specificity, we examined whether plasmin causes detachment of endothelium, thus affecting the adherence determination. Fig. 3 shows light micrographs of normal endothelial cells and endothelial cells incubated with plasmin $\left(10^{-8}\right.$ M) or phorbol myristate acetate PMA $(30 \mathrm{ng} / \mathrm{ml})$ for $60 \mathrm{~min}$. Endothelial cells maintained their cobblestone morphology and did not detached from the matrix. The finding that catalytically inhibited plasmin also induced neutrophil adhesion (see below) argues against the increase in adherence resulting from nonspecific protease-induced detachment of endothelial cells.

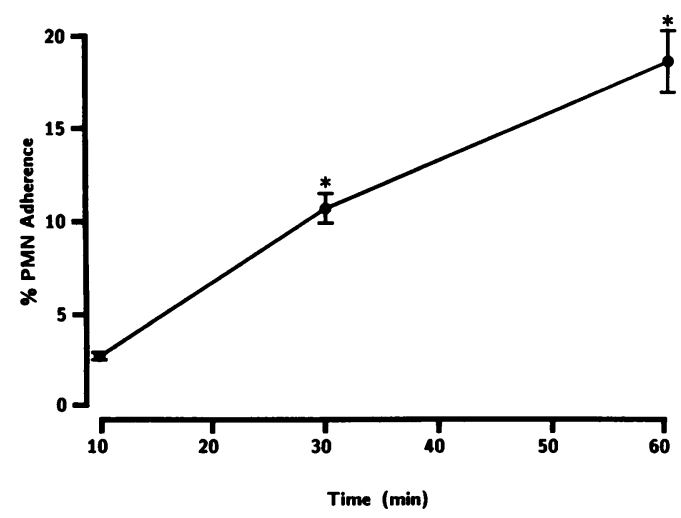

Figure 1. Effect of porcine plasmin incubation time on neutrophil adherence. Endothelial monolayers were coincubinated with neutrophils $\left(2 \times 10^{6}\right.$ cells per well) and plasmin $\left(10^{-8} \mathrm{M}\right)$ at $37^{\circ} \mathrm{C}$ for 10 , 30 , and $60 \mathrm{~min}$. Basal adherence to endothelial cells was $6.2 \pm 0.4 \%$ after $60 \mathrm{~min}$ incubation. Values are expressed as mean \pm SEM. Each point represents five replicate wells.

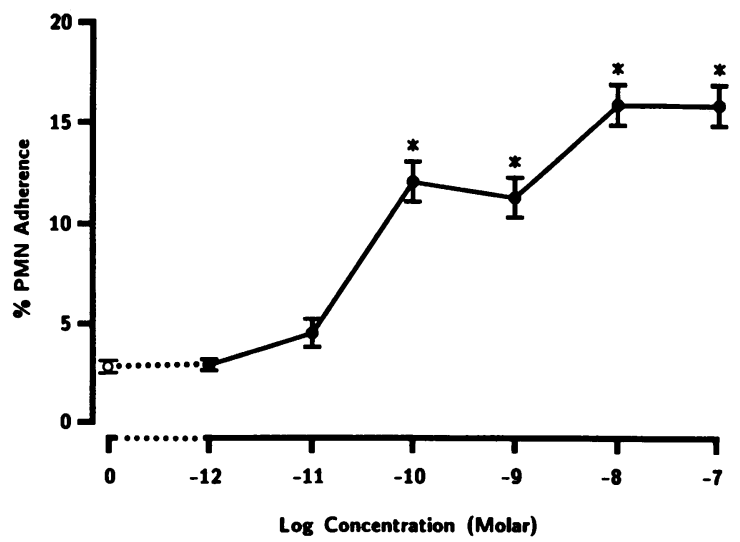

Figure 2. Concentration dependence of porcine plasmin on sheep neutrophil adherence to monolayers of SPAE. Increasing concentrations of plasmin were added to the wells to which neutrophils had been previously added. $\left(2 \times 10^{6}\right.$ cells per well.) Values are expressed as means \pm SEM. $O$, zero concentration of plasmin. Note that increases in adherence were observed at plasmin concentrations $>10^{-10} \mathrm{M}$. Each point represents eight replicate wells.

We assessed whether plasmin exerted its adherence-promoting effects on endothelial cells and/or neutrophils. In the first experiment, endothelial cell monolayers were pretreated with plasmin before adherence assay carried out with freshly obtained neutrophils (Table I). Adherence of neutrophils to plasmin-pretreated endothelial cell monolayers was similar to basal adherence. Addition of plasmin to washed endothelial cells that had been pretreated with plasmin resulted in an adherence response. We next incubated neutrophils with plasmin for $30 \mathrm{~min}$ and washed the neutrophils before their addition to unstimulated endothelial cell monolayer. These neutrophils demonstrated increased adherence to the endothelium, which was comparable to that observed when plasmin $\left(10^{-8} \mathrm{M}\right)$ was added to the mixed cell cultures of endothelial cells and neutrophils. Neutrophils remained viable during the $30-\mathrm{min}$ plasmin incubation period before washing.

The effect of plasmin on neutrophils was studied using sheep neutrophils and endothelial cells; however, the response was not species dependent. Human plasmin induced a comparable adhesion of human neutrophils to HUVEC (percent adherence increased from basal value of $2 \pm 1$ to $18 \pm 1 \%$ [ $n=6]$ with $10^{-8} \mathrm{M}$ plasmin). Moreover, human plasmin $\left(10^{-8} \mathrm{M}\right)$ did not significantly increase adherence of human neutrophils to human ocular fibroblasts (basal adherence of $3 \pm 0.3$ to $5 \pm 0.3 \%$ with plasmin $)(n=3)$.

We determined whether the plasmin-induced adhesion of neutrophil was mediated by increased CD18 activity of neutrophils by assessing the response in the presence of antibodies against the $\beta$ chain of the CD18 neutrophil adhesive glycoprotein complex (MAbs 60.3 and IB4). The data are summarized in Table II. Both MAbs 60.3 and IB4 inhibited the adhesion of neutrophil induced by plasmin. In contrast, the isotypic control MAb 60.5 (targeted against the HLA class I antigen on peripheral leukocytes) did not reduce neutrophil adherence, indicating the specificity of the inhibitory effects of MAbs 60.3 and IB4. We examined whether plasmin resulted in an increased expression of CD18 on neutrophil cell membrane, and thereby contributing to the CD18-dependent neutrophil adhe- 

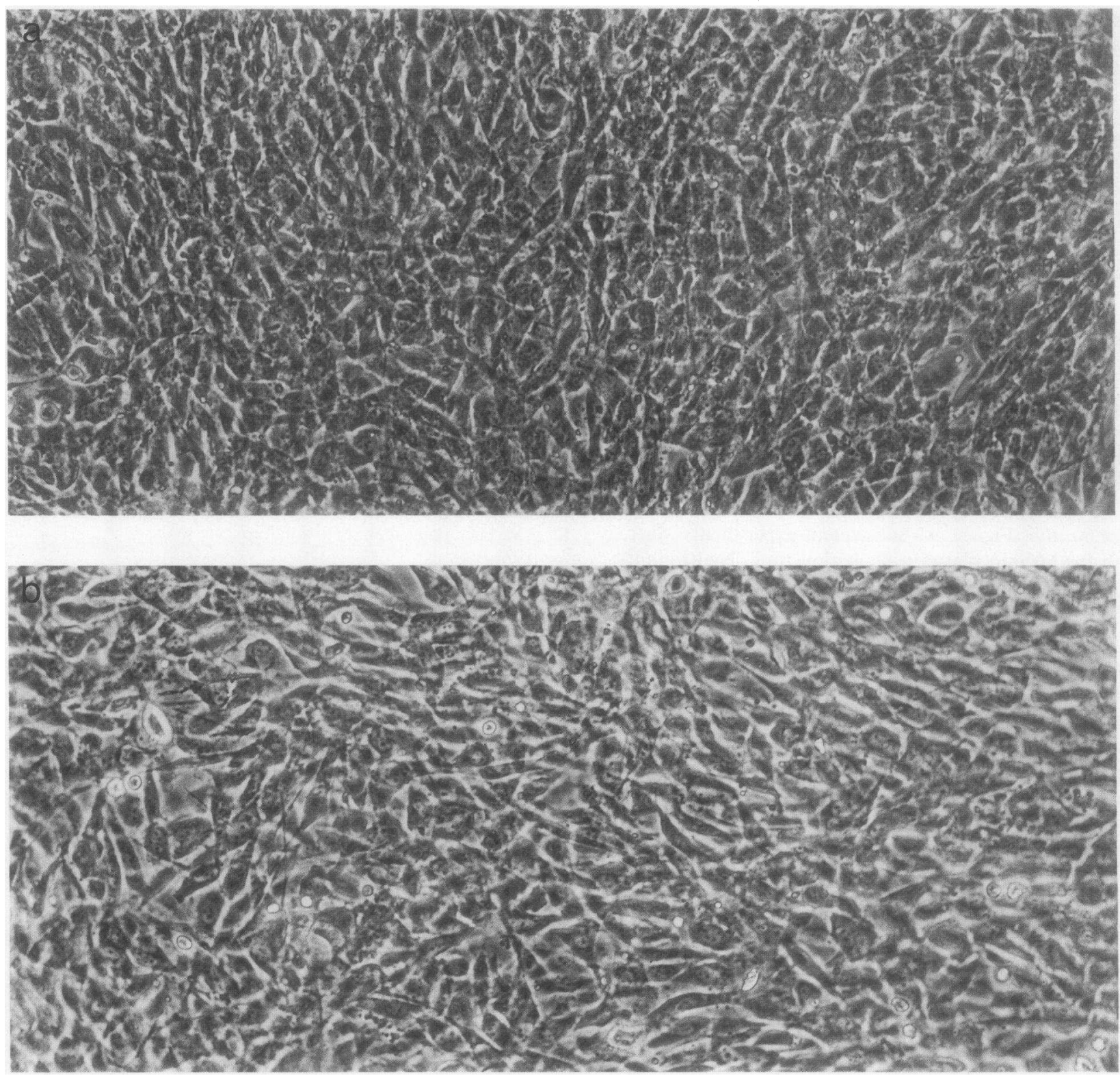

Figure 3. Phase-contrast micrographs $(\times 200)$ of neutrophil adhesion to cultured endothelial cell monolayer $(a)$ Control SPAE cell monolayer (EC), (b) after adding sheep neutrophils ( $10^{6}$ total) suspended in DME, added to confluent endothelial monolayers 60 min and then washed three times, few neutrophils are adherent, $(c)$ increased number of neutrophils were attached to endothelial monolayer after adding plasmin $\left(10^{-8} \mathrm{M}\right)$ for $60 \mathrm{~min}$ and subsequently washing three times (note that the integrity of endothelial monolayer was not affected by plasmin), and (d) an increased number of neutrophils were aggregated and adherent to the endothelial monolayer after addition of $30 \mathrm{ng}$ PMA.

sion. FACS analysis using FITC-IB4 on plasmin-stimulated neutrophils indicated that plasmin did not increase CD18 expression. The mean channel of fluorescence for unstimulated sheep neutrophils was 135 , and this value was not different from value of 128 after treatment with plasmin $\left(10^{-8} \mathrm{M}\right)$ for 60 $\min (n=3)$. In contrast, stimulation with PMA $(30 \mathrm{ng} / \mathrm{ml})$ for $15 \mathrm{~min}$ resulted in a threefold increase of mean channel fluorescence.

The time course of the reversibility plasmin's effect on neutrophils was examined by washing plasmin-treated neutrophils to remove residual plasmin and adding fresh DME to assay wells and incubating them for varying time intervals at $37^{\circ} \mathrm{C}$. Neutrophil adherence remained elevated above basal adherence up to $30 \mathrm{~min}$ after plasmin challenge (Fig. 4).
The catalytic site of plasmin was blocked irreversibly with either DFP, Trasylol, or $\alpha_{2}$-PI to determine whether the active site on plasmin is a determinant of increased neutrophil adhesiveness. The catalytic activity of plasmin was inhibited in each case by $>99.9 \%$. DFP treatment did not significantly affect the ability of plasmin to induce neutrophil adherence (percent adherence of $16 \pm 3 \%$ vs. adherence induced by plasmin of $20 \pm 3 \%$ ) (Fig. 5). Trasylol (a serine protease inhibitor of larger molecular size, $\left.M_{\mathrm{r}}=6,500\right)$ also did not reduce the adherence (Fig. 5); moreover, addition of excess Trasylol (150 $\mathrm{U} / \mathrm{ml})$ to plasmin $\left(10^{-8} \mathrm{M}\right)$ did not modify the plasmin effect (percent adherence $=18 \pm 1 \%$ ). In contrast, $\alpha_{2}-\mathrm{PI}$ inhibited the effect of plasmin in promoting neutrophil adherence (percent adherence of $7 \pm 2 \%$ ) (Fig. 5). 

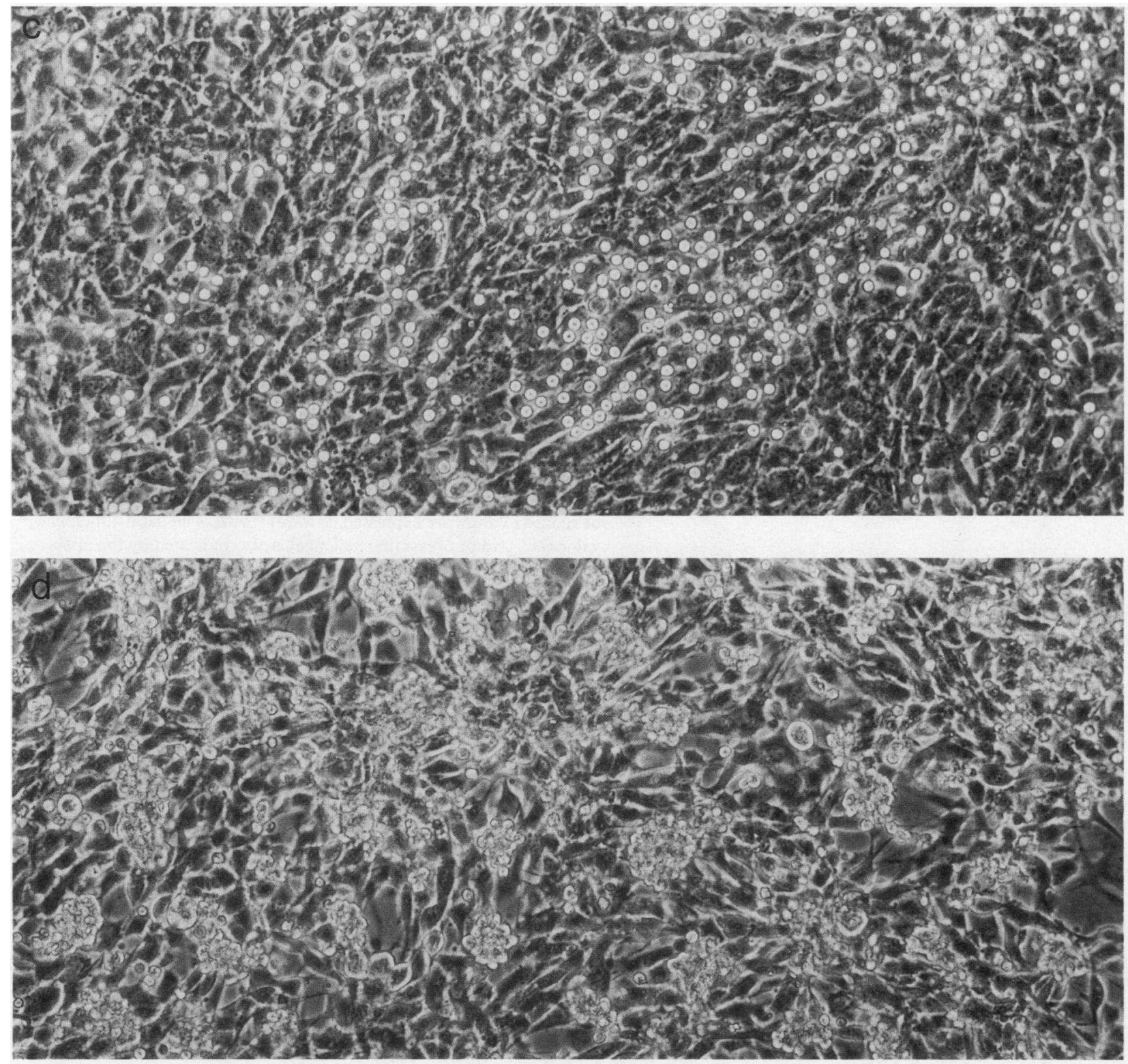

Figure 3 (Continued)

Lys-plasminogen (plasminogen minus residues $1-76)\left(10^{-8}\right.$ M) also possessed the ability to induce neutrophil adherence (percent adherence of $18 \pm 0.3 \%$ vs. active plasmin value of $29 \pm 3 \% ; n=3$ ). The effect of plasmin was greater than lysplasminogen at $10^{-8} \mathrm{M}(P<0.05)$. Unlike the lys-plasminogen, glu-plasminogen $\left(10^{-7}\right.$ or $\left.10^{-8} \mathrm{M}\right)$ (the native molecule) did not have an adherence-inducing effect (percent adherence of $7 \pm 1 \%$ ). The plasmin contamination of these two plasminogen preparations was $<0.1 \%$ as assessed by the chromogenic substrate assay (see Methods). The plasmin specificity of the response was further demonstrated by testing two kringle-containing proteins, tissue plasminogen activator (human tissue plasminogen activator purchased from American Diagnostica) and human urokinase (WinKinase; 250,000 U/vial, from Winthrop Labs, Rensselaer, NY) in the adherence assay. Urokinase $(n=3)$ and tissue plasminogen activator $(n=3)$ at $10^{-8}$ $M$ had no stimulatory effect (percent adherence of $5 \pm 0.2$ and
$5 \pm 0.4 \%$, respectively) compared with a control adherence of $5 \pm 1 \%(n=3)$ and $10^{-8} \mathrm{M}$ plasmin response of $19 \pm 2 \%(n=3)$.

Three purified elastase-digested plasminogen fragments (see Introduction) were used to examine the molecular domain of plasmin responsible for the neutrophil adherence-inducing activity: (a) kringle $1+2+3(\mathrm{~K} 1+2+3),(b)$ kringle $4(\mathrm{~K} 4)$, and (c) miniplasminogen ( $\mathrm{K} 5+$ the light chain). These plasminogen fragments were used at equivalent concentrations of $10^{-8}$ $M$ (the residual plasmin activity was $<0.1 \%$ in each kringle fragment). The neutrophil adherence-inducing responses were compared with native plasmin. Both $\mathrm{K} 1+2+3$ and $\mathrm{K} 4$ had stimulatory effects (Table III), and responses were similar to native enzyme. In contrast, $\mathrm{K} 5+$ the light chain, which lacks LBS, had no significant effect (Table III). Using a mixture of miniplasminogen and miniplasmin, neutrophil adherence response was identical to that of miniplasminogen (percent adherence $=7 \pm 1 \%[n=7])$. 
Table I. Effects of Plasmin Pretreatment of Neutrophils or Endothelial Cells on Neutrophil Adherence

\begin{tabular}{lccc}
\hline \multicolumn{1}{c}{ Treatments } & $n$ & Adherence & $P$ \\
\hline & & $\%$ & \\
Basal & 5 & $4 \pm 1$ & \\
Plasmin pretreated PMN & 5 & $14 \pm 2$ & $<0.05$ \\
Plasmin pretreated EC & 3 & $6 \pm 1$ & NS \\
Plasmin pretreated EC + plasmin & 3 & $12 \pm 2$ & $<0.05$ \\
Plasmin coincubation with PMN and EC & 3 & $15 \pm 4$ & $<0.05$ \\
& & & \\
\hline
\end{tabular}

Plasmin (porcine) concentration was $10^{-8} \mathrm{M}$. Neutrophil adherence was measured after $60 \mathrm{~min}$ incubation time. Pretreatment of ovine neutrophils (PMN) or ovine endothelial cells (EC) were carried out with $10^{-8} \mathrm{M}$ plasmin for $30 \mathrm{~min}$, and plasmin was removed by gentle washing with DME. Statistical comparisons ( $t$ tests) were made with basal adherence where only DME was added.

* Numbers of separate experiments; the mean of one experiment consists of six to eight determinations.

The role of the LBS in plasmin-induced neutrophil adherence was further evaluated using the LBS ligand, tranexamic acid (TX), which inhibits plasminogen binding to fibrinogen, fibrin, and endothelial cells $(8,10)$. Viability of neutrophils was $>99 \%$ by trypan blue exclusion after incubation period of $60 \mathrm{~min}$ with TX. The capacity of TX to inhibit the effect of plasmin was concentration dependent (Fig. 6). The $\mathrm{IC}_{50}$ was 5 $\mathrm{mM}$ and adherence was not affected by TX concentrations $<0.01 \mathrm{mM}$. TX reduced the adherent response induced by plasmin and by $\mathrm{K} 1+2+3$ and $\mathrm{K} 4$ (Table IV). The monospecific polyclonal antibody directed against the $\mathrm{K} 1+2+3 \mathrm{LBS}$ complexed with plasmin also produced $47 \%$ inhibition of adherence (Table V).

\section{Discussion}

This study demonstrates that plasmin induces neutrophil adherence to cultured endothelial cell monolayers. Plasmin

Table II. Effects of MAb Directed against $\beta$ chain of Neutrophil CD18 on Plasmin-induced Neutrophil Adhesion to Endothelial Cell Monolayers

\begin{tabular}{lrr}
\hline & \multicolumn{2}{c}{ PMN adherence } \\
\cline { 2 - 3 } Treatments & \multicolumn{1}{c}{ Exp. 1 } & Exp. 2 \\
\hline & $2 \pm 1$ & \\
Control & $13 \pm 1$ & $4 \pm 1$ \\
Plasmin & $6 \pm 1$ & $16 \pm 1$ \\
MAb IB4 + plasmin & $4 \pm 1$ & $6 \pm 1$ \\
MAb 60.3 + plasmin & $12 \pm 1$ & $6 \pm 1$ \\
MAb 60.5 + plasmin & & $20 \pm 3$ \\
& & \\
\hline
\end{tabular}

Values are means \pm SEM of five to eight determinations. Ovine neutrophils were treated with porcine plasmin $\left(10^{-8} \mathrm{M}\right)$ at $37^{\circ} \mathrm{C}$ for 30 min. MAb was added to neutrophil suspension to achieve a final concentration of $10 \mu \mathrm{g} / \mathrm{ml}$. MAb IB4 and 60.3 recognize the $\beta$ chain of CD18 and isotypic MAb 60.5 recognizes the HLA class I antigen on all leukocytes. Note that the control MAb 60.5 did not have any inhibitory effect.

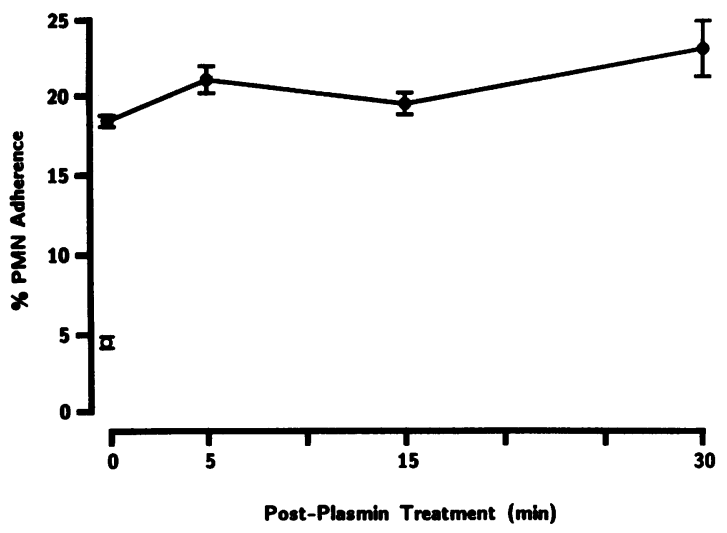

Figure 4. Time course of the adhesive effect induced by porcine plasmin on neutrophils after washing. PMN were treated with plasmin $\left(10^{-8} \mathrm{M}\right)$ for $60 \mathrm{~min}$ and then washed once with DME. Washed PMN suspensions were then put back to into $\mathrm{CO}_{2}$ incubator for the various times indicated before addition to assay wells. Note that PMN remained adhesive to endothelium at $30 \mathrm{~min}$ after the removal of agonist. Values are expressed as mean \pm SEM. The basal adherence value (i.e., without plasmin challenge) is also indicated by the open circle. Each point represents eight replicate wells.

exerts its adherence-promoting effect by an action on neutrophils rather than endothelial cells since preincubation of endothelial cells with plasmin did not result in increased endothelial adhesiveness. The adhesive response was independent of the plasmin catalytic activity since the DFP- or Trasyloltreated plasmin induced a similar response as native plasmin. However, the $67-\mathrm{kD}$ serine protease inhibitor, $\alpha_{2}$-PI (which complexes with a larger portion of plasmin molecule) markedly reduced plasmin-induced neutrophil adherence. $\alpha_{2}$-PI blocks the catalytic site and also interferes with the LBS, an effect related to its large molecular size (3). The finding that $\alpha_{2}$-PI inhibited the plasmin-induced adherence response suggests that noncatalytic regions of plasmin that bind to $\alpha_{2}$-PI such as LBS may mediate the response.

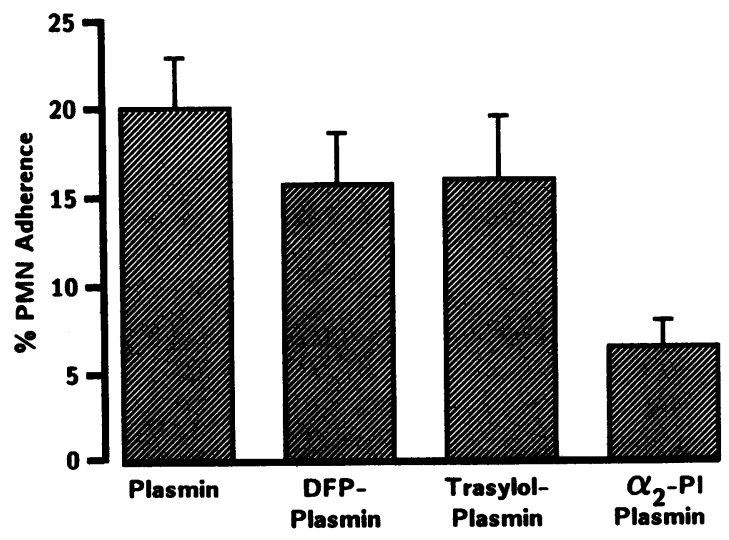

Figure 5. Effect of inhibitors on neutrophil adhesion to cultured endothelial cell monolayers. The catalytic site of porcine plasmin was irreversibly blocked with either DFP, Trasylol, or $\alpha_{2}$-PI. In all cases, the catalytic activity of plasmin was reduced $>99.9 \%$. Note that only $\alpha_{2}$-PI inhibited plasmin response, whereas DFP-plasmin and Trasylol-plasmin had an adherence-promoting effect compared with plasmin. Each point represents the average of eight replicate wells. 
Table III. Neutrophil Adhesion Induced by Plasmin and Plasminogen Fragments

\begin{tabular}{lccc}
\hline \multicolumn{1}{c}{ Treatments } & $n^{*}$ & Adherence & $P$ \\
\hline & & $\%$ & \\
Plasmin & 7 & $17 \pm 3$ & - \\
K1 $+2+3$ & 8 & $17 \pm 1$ & NS \\
K4 & 8 & $14 \pm 1$ & NS \\
K5 + light chain & 3 & $6 \pm 1$ & $<0.05$ \\
Control & 8 & $3 \pm 1$ & $<0.05$ \\
& & &
\end{tabular}

* Number of separate experiments; each experiment consists of six to eight determinations; adhesion was assessed using ovine neutrophils. Values are means \pm SEM. The $t$ test compares the adherence in the presence of plasminogen fragments or plasmin at $10^{-8} \mathrm{M}$. Note that K5 + light chain is not different from control.

Several other lines of evidence support the conclusion that LBS on plasmin are crucial in mediating the neutrophil adherence-promoting activity of plasmin: (a) fragments $\mathrm{K} 1+2+3$ and $\mathrm{K} 4$ containing LBS possessed identical adherence-promoting activity to native plasmin, whereas the elastase-derived fragment lacking LBS (K5 + light chain) had no effect, $(b)$ the adherence-inducing activity of plasmin and of the fragments was inhibited by TX that binds to LBS; and (c) a monospecific polyclonal antibody directed against the LBS of $\mathrm{K} 1+2+3$ markedly reduced the plasmin-induced neutrophil adherence.

There are two classes of LBS on kringle $1+2+3$, one site with high affinity $\left(K_{d}=9 \mu \mathrm{M}\right)$ for the lysine analog $\epsilon$-amino caproic acid, and others with low affinity $\left(K_{d}=5 \mathrm{mM}\right)(5)$, all of which may participate in inducing the neutrophil adherence. Note, however, that although the K4 fragment possesses neutrophil adherence-promoting activity, this may be applicable only to in vitro conditions because the LBS on kringle 4 of plasmin is unoccupied in the presence of fibrinogen and $\alpha_{2}$-PI (34). Our observation that plasmin inhibited with $\alpha_{2}$-PI does not cause neutrophil adherence indicates that LBS on kringle 4 of the intact plasmin molecule does not participate in the ad-

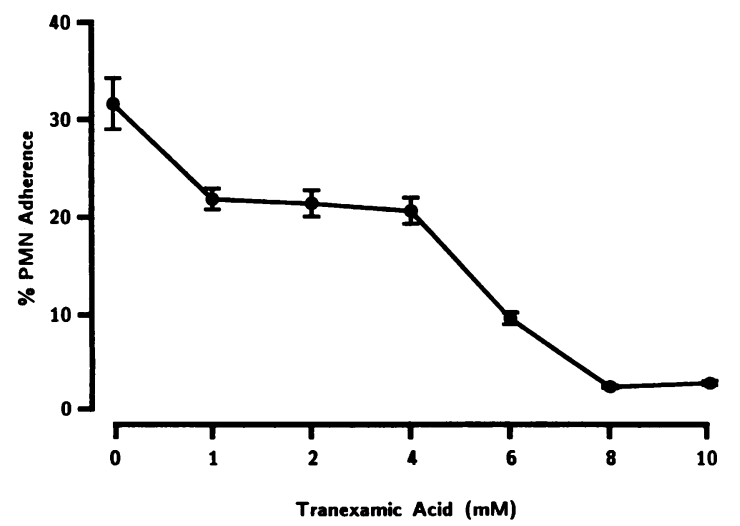

Figure 6. Dose-dependent inhibition of porcine plasmin-induced neutrophil adherence to endothelial cell monolayers by TX. TX caused a dose-related inhibition with $\mathrm{IC}_{50}$ of $5 \mathrm{mM}$. The neutrophil adherence inducing effect of plasmin was abolished at $10 \mathrm{mM}$ TX. Plasmin concentration is $10^{-8} \mathrm{M}$. Each point represents eight replicate wells.
Table IV. Effects of $1 \mathrm{mM} T \mathrm{TX}$ on Neutrophil Adherence to Cultured Endothelial Cell Monolayers Induced by Plasmin and Plasminogen Fragments

\begin{tabular}{lc}
\hline \multicolumn{1}{c}{ Treatments } & Adherence \\
\hline & $\%$ \\
Plasmin & $27 \pm 2$ \\
Plasmin + TX & $19 \pm 2$ \\
K1 $+2+3$ & $19 \pm 2$ \\
K1 $+2+3+$ TX & $10 \pm 1$ \\
K4 & $25 \pm 3$ \\
K4 + TX & $10 \pm 2$ \\
PMA $(30 ~ n g / m l)$ & $84 \pm 1$ \\
PMA $(30 n g / m l)+$ TX & $79 \pm 2$
\end{tabular}

* Data represent results of one experiment. Similar findings were obtained in five separate experiments. The cells were ovine neutrophils and ovine endothelial cells. Basal adherence was $4 \pm 1 \%$. Percent inhibition caused by $1 \mathrm{mM}$ TX for plasmin, $\mathrm{K} 1+2+3$ and $\mathrm{K} 4$ are 30 , 47 , and $60 \%$, respectively. Note that TX did not alter the neutrophil adherence induced by PMA, a stimulant whose action is not mediated by LBS.

herence-promoting response. This is in agreement with the concept that LBS on K4 is not normally accessible (34). However, this site becomes accessible in the elastase-derived $\mathrm{K} 4$ fragment $(3,34)$, which probably accounts for the activity of $\mathrm{K} 4$ in inducing neutrophil adherence.

The response was specific to plasmin because glu-plasminogen, the native proenzyme, did not induce neutrophil adherence. The observation that lys-plasminogen lacking amino acids 1-76 (which is generated during fibrinolytic activation $[2,3])$ produced neutrophil adherence but to a lesser extent than plasmin, supports the notion that neutrophil adhesion can occur as consequence of plasmin generation. The greater potency of plasmin versus lys-plasminogen may be the result of a specific conformational change occurring in the plasmin molecule. This altered LBS on plasmin is sufficient to explain the specificity of plasmin in eliciting the adhesion response. The lack of neutrophil adherence with glu-plasminogen is consistent with the observed differences in LBS binding affini-

Table V. Effects of a Polyclonal Monospecific Antibody (Ab) Directed against $K 1+2+3$ LBS on Plasmin-induced Neutrophil Adherence to Endothelial Cells

\begin{tabular}{lccc}
\hline \multicolumn{1}{c}{ Treatments } & $n$ & Adherence & $P$ \\
\hline & & $\%$ & \\
Control & 5 & $4 \pm 1$ & - \\
Plasmin & 5 & $17 \pm 2$ & - \\
Plasmin $+\mathrm{Ab}$ & 5 & $9 \pm 1$ & $<0.05$ \\
\hline
\end{tabular}

The $t$ test is performed comparing groups plasmin and plasmin $+\mathrm{Ab}$ groups. Cells were ovine neutrophils and ovine endothelial cells. Control represents absence of plasmin and antibody. The values are means \pm SEM. Plasmin was preincubated with $A b$ ( $1: 50$ dilution) for $10 \mathrm{~min}$ at room temperature to block the LBS of plasmin before the adherence assay. 
ties to fibrin and fibrinogen seen with lys-plasminogen versus glu-plasminogen (8). The specificity of the response to LBS of plasmin was supported by our finding that urokinase and tissue plasminogen activator, proteins with kringle structures, did not stimulate neutrophil adherence.

Thrombin has also been shown to cause neutrophil adherence to endothelium $(23,29)$; however, thrombin, unlike plasmin, exerts its effects on the endothelium $(23,29)$ by expression of adhesive sites on the endothelium (29) and by generation of mediators (23). Plasmin exerts its effect on neutrophils and does not increase endothelial adhesiveness. The action of plasmin is independent of its catalytic site, whereas thrombin's response requires the catalytic site because antithrombin III and hirudin-inactivated thrombin inhibited neutrophil adherence induced by thrombin (29).

The CD18 glycoprotein complex of peripheral leukocyte is an important determinant of leukocyte adhesion to the endothelium $(21,26,30)$. MAbs IB4 and 60.3 directed against the $\beta$ chain of CD18 complex $(21,35)$ inhibited the plasmin-induced neutrophil adherence. Therefore, neutrophil adherence induced by plasmin is mediated by increased CD18 activity and this adhesion domain resides on the $\beta$ chain of the heterodimer complex. The inhibitory response is specific because the control MAb 60.5 did not reduce neutrophil adherence.

Although plasmin resulted in neutrophil adhesion, it did not increase neutrophil CD18 expression as assessed by FACS analysis; therefore, the adherence response is likely mediated by an increased functional activity of the neutrophil CD18 without an increase in glycoprotein expression. In previous studies, quantitative changes in CD18 expression also do not correlate well with the functional adhesive activity of CD18 (30). For example, a temperature change from 4 to $37^{\circ} \mathrm{C}$ caused an increase in CD18 expression but did not increase neutrophil adherence (36). Moreover, stimulation of cytoplasts (neutrophils without granules) did not induce CD18 expression, although cytoplasts were capable of adhering to endothelium via increased CD18 activity (37). Detmers et al. (38) have reported a temporal correlation between formation of CR3 microaggregates on neutrophil cell surface and CR3 binding activity, suggesting that CD18 clustering may be responsible for increased CD18 functional activity.

In contrast to the effect of plasmin in promoting neutrophil adherence to the endothelium, plasmin did not result in neutrophil adherence to a confluent layer of ocular fibroblasts. This result indicates the specificity of the response with respect of adherence to endothelial cells, and also suggests that an interaction occurs between the neutrophil adhesive glycoprotein CD18 and sites on the endothelium.

The action of plasmin in inducing neutrophil adherence is comparable in magnitude and time course to other neutrophil adhesion-promoting mediators such as C5a and FLMP, which act primarily on neutrophils (17). These agents also increase neutrophil adhesiveness over a short time (i.e., within $1 \mathrm{~h}$ ). The rapidity of the adherence response is compatible with increased functional activity of CD18 without translocation of CD18 glycoprotein from the cytoplasmic storage granules to the cell surface (39). The persistence of the plasmin effect for up to $30 \mathrm{~min}$ after washing is in contrast to effects of other mediators such as $\mathrm{C} 5 \mathrm{a}$ (17) and $\mathrm{LTB}_{4}(20)$, which result in a rapid modulation of neutrophil adherence.

The results of this study may have pathophysiological significance because the generation of plasmin can have conse- quences in the inflammatory response $(1,40)$. It is known that fibrinolytic activation leading to free plasmin generation (1) induces proteolysis of plasma proteins $(17,18)$ and platelet aggregation and activation, $(16,41,42)$. In addition, as these results indicate, free plasmin induces neutrophil adherence, which may result in intravascular neutrophil sequestration and may have a proinflammatory role at the vessel wall surface.

\section{Acknowledgments}

We express our thanks to Dr. P. C. Harpel for generously providing the $\alpha_{2}$-PI, Dr. S. D. Wright for supplying the MAb IB4 and permission for use of the FACScan, Dr. P. Del Vecchio for proving human vascular fibroblasts, and Dr. J. Harlan and Dr. P. Beattie for supplying MAbs 60.3 and 60.5. We also thank Carol Anne Leahy and Lynn McCarthy for their excellent secretarial assistance.

This work was supported by PO1 HL-32418, RO1 HL-31046, and RO1 HL-17016 from the National Institutes of Health, and The American Heart Association, New York Affiliate.

\section{References}

1. Collen, D. 1987. Molecular mechanisms of fibrinolysis and their application to fibrin-specific thrombolytic therapy. Cell. Biochem. 33:77-86.

2. Robbins, K. C. 1977. The biochemistry of plasminogen to plasmin. In Hemostasis: Biochemistry, Physiology and Pathology. D. Ogstmand and A. B. Bennet, editors. John Wiley \& Sons, New York/ London. 208-217.

3. Ryan, T. J. 1987. Photoaffinity labelling of human plasmin and plasminogen. Pharmacol. Ther. 34:335-348.

4. Sottrup-Jensen, L., H. Claeys, M. Zajdel, T. E. Peterson, and S. Magnusson. The primary structure of human plasminogen: isolation of two lysine-binding fragments and one "mini"-plasminogen (M.W. $38,000)$ by elastase catalyzed-specific limited proteolysis. Prog. Chem. Fibrinolysis Thrombolysis. 3:191-209.

5. Lerch, P. G., E. E. Rickli, W. Lergier, and D. Gillessen. 1980. Localization of individual lysine-binding regions in human plasminogen and investigations on their complex-forming properties. Eur. $J$. Biochem. 107:7-13.

6. Markus, G., J. L. DePasquale, and F. C. Wissler. 1978. Quantitative determination of the binding of aminocaproic acid to native plasminogen. J. Biol. Chem. 253:727-732.

7. Vali, Z., and L. Patthy. 1982. Location of the intermediate and high affinity $\epsilon$-aminocarboxylic acid-binding sites in human plasminogen. J. Biol. Chem. 257:2104-2110.

8. Lucas, M. A., L. J. Fretto, and P. A. McKee. 1983. The binding of human plasminogen to fibrin and fibrinogen. J. Biol. Chem. 258:4249-4256.

9. Bauer, P. I., R. Machovich, K. G. Buki, E. Csonka, S. A. Kock, and I. Horvath. 1984. Interaction of plasmin with endothelial cells. Biochem. J. 218:119-124.

10. Hajjar, K. A., P. C. Harpel, E. A. Jaffe, and R. L. Nachman. 1986. Binding of plasminogen to cultured human endothelial cells. $J$. Biol. Chem. 261:11656-11662.

11. Miles, L. A., M. H. Ginsberg, J. G. White, and E. F. Plow. 1986. Plasminogen interacts with human platelets through two distinct mechanisms. J. Biol. Chem. 77:2001-2009.

12. Miles, L. A., and E. F. Plow. 1986. Binding and activation of plasminogen on the platelet surface. J. Biol. Chem. 260:4303-4311.

13. Niewiarowski, S., A. F. Senyi, and P. Gillis. 1975. Plasmin-induced platelet aggregation and platelet release reaction. J. Clin. Invest. 52:1647-1659.

14. Plow, E. F., D. E. Freaney, J. Plescia, and L. A. Miles. 1986. The plasminogen system and cell surfaces: evidence for plasminogen and urokinase receptors on the same cell type. J. Cell Biol. 103:24112420. 
15. Schafer, A. I., A. K. Maas, A. Ware, P. C. Johnson, S. E. Rittenhouse, and E. W. Salzman. 1986. Platelet protein phosphorylation, elevation of cytosolic calcium and inositol phospholipid breakdown in platelet activation induced by plasmin. J. Clin. Invest. 78:7379.

16. Guccione, M. A., R. LikinLough-Rathbone, M. A. Pacham, E. J. Harfenist, M. L. Rand, J. P. Greenberg, D. W. Perry, and J. F. Mustard. 1985. Effect of plasmin on rabbit platelet. Thromb. Hemostasis. 53:8-14.

17. Cooper, J. A., S. K. Lo, and A. B. Malik. 1988. Fibrin is a determinant of pulmonary neutrophil sequestration. Circ. Res. 63:735-741.

18. Malik, A. B. 1985. Mediators of pulmonary vascular injury and edema after thrombin. In The Pulmonary Circulation and Acute Lung Injüry. S. I. Said, editor. Futura Publishing Co., Mount Kisko, NY. 429-454.

19. Tonnesen, M. G., L. A. Smedly, and P. M. Henson. 1984. Neutrophil-endothelial cell interactions. Modulation of neutrophil adhesives induced by complement fragments C5a and C5a des arg and formyl-methionyl-leucyl-phenylalanine in vitro. J. Clin. Invest. 74:1581-1592.

20. Gimbrone, M. A., Jr., A. F. Brock, and A. I. Schafer. 1984. Leukotriene $\mathrm{B}_{4}$ stimulates polymorphonuclear leukocyte adhesion to cultured vascular endothelial cells. J. Clin. Invest. 74:1552-1555.

21. Harlan, J. M., P. D. Killon, F. M. Senecal, B. R. Schwartz, E. K. Yee, F. R. Taylor, P. G. Beatty, and T. H. Price. 1985. The role of neutrophil membrane protein GP-150 in neutrophil adhesion to endothelia in vitro. Blood. 66:167-178.

22. Pohlman, T. H., K. A. Stanness, P. G. Beatty, H. D. Ochs, and J. M. Harlan. 1986. An endothelial cell surface factor(s) induced in vitro by lipopolysacharide, interleukin 1 , and tumor necrosis factor $\mathrm{a}_{\mathrm{a}}$ increases neutrophil adherence by a CDw18-dependent mechanism. $J$. Immunol. 136:4548-4553.

23. Zimmerman, G. A., T. M. McIntyre, and S. M. Prescott. 1985. Thrombin stimulates the adherence of neutrophils to human endothelial cells in vitro. J. Clin. Invest. 76:2235-2246.

24. Bevilacqua, M. P., J. S. Pober, M. E. Wheeler, R. S. Cotran, and M. A. Gimbrone, Jr. 1985. Interleukin 1 acts on cultured human vascular endothelial to increase the adhesion of polymorphonuclear leukocytes, monocytes, and related leukocyte cell lines. J. Clin. Invest. 76:2003-2011.

25. Schleimer, R. P., and B. K. Rutledge. 1986. Cultured human vascular endothelial cells acquire adhesiveness for neutrophils after stimulation with interleukin 1, endotoxin, and tumor-promoting phorbol diesters. J. Immunol. 136:649-654.

26. Anderson, D. C., and T. A. Springer. 1987. Leukocyte adhesion deficiency: an inherited defect in the Mac-1, LFA-1, and p150,95 glycoproteins. Annu. Rev. Med. 38:175-194.

27. Gilboa, N., and J. E. Kaplan. 1985. Plasma fibronectin enhances fibrinolytic system in vitro. Thromb. Hemostasis. 54:639-644.

28. Ryan, T. J., and M. C. Keegan. 1985. Photoaffinity labelling of functionally different lysine-binding sites in human plasminogen and plasmin. Biochim. Biophys. Acta. 830:187-194.

29. Bizios, R., L. Lai, J. A. Cooper, P. J. Del Vecchio, and A. B. Malik. 1988. Thrombin-induced adherence of neutrophils to cultured endothelial monolayers: increased endothelial adhesivity. J. Cell. Physiol. 134:275-280.

30. Wright, S. D., and B. C. Meyer. 1986. Phorbol esters cause sequential activation and deactivation of complement receptors on polymorphonuclear leukocytes. J. Immunol. 136:1759-1764.

31. Miles, L. A., and E. F. Plow. 1986. Topography of the high-affinity lysine binding site of plasminogen as defined with a specific antibody probe. Biochemistry. 25:6926-6933.

32. Cooper, J. A., S. J. Solano, R. Bizios, J. E. Kaplan and A. B. Malik. 1984. Pulmonary neutrophil kinetics after thrombin-induced intravascular coagulation. J. Appl. Physiol. 57:826-832.

33. Del Vecchio, P. J., R. Bizios, L. A. Holleran, T. K. Judge, and G. L. Pinto. 1988. Inhibition of human scleral fibroblast proliferation with heparin. Invest. Opthalmol. \& Visual Sci. 29:1272-1276.

34. Plow, E. F., and D. Collen. 1981. Immunochemical characterization of a low affinity lysine binding site within plasminogen. J. Biol. Chem. 256:10864-10869.

35. Wright, S. D., P. E. Rao, W. C. Van Voorhis, L. S. Craigmyle, K. Iida, M. A. Talle, G. Goldstein, and S. C. Silverstein. 1983. Identification of the C3bi receptor on human monocytes and macrophages by using monoclonal antibodies. Proc. Natl. Acad. Sci. USA. 80:5699-5703.

36. Buyon, J. P., M. Phillips, J. Dalton, S. Abramson, G. Weissmann, and R. Winchester. 1987. Disassociation between the phenomenon of gp 165/95 (CR3) mediated granulocyte aggregation and the quantity of $\mathrm{gp} 165 / 95$ expressed on the cell surface. Evidence for two functionally distinct forms of gp 165/95. Clin. Res. 35:469a. (Abstr.)

37. Vedder, N. B., and J. M. Harlan. 1988. Increased surface expression of CD1 lb/CD18 (Mac-1) is not required for stimulated neutrophil adherence to cultured endothelium. J. Clin. Invest. 81:676682.

38. Detmers, P. A., S. D. Wright, E. Olsen, B. Kimball, and Z. A. Cohn. 1987. Aggregation of complement receptors on human neutrophils in the absence of ligand. J. Cell Biol. 105:1137-1145.

39. Todd, R. F. III, M. A. Arnaout, M. A., R. E. Rosin, C. A. Crowley, W. A. Peters, and B. M. Babior. 1984. Subcellular localization of the large subunit of Mol (Mol: formerly gp110), a surface glycoprotein associated with neutrophil adhesion. J. Clin. Invest. 74:1280-1290.

40. Malik, A. B. 1983. Pulmonary microembolism. Physiol. Rev. 63:1114-1207.

41. Miles, L. A., and E. F. Plow. 1987. Receptor mediated binding of the fibrinolytic components plasminogen and urokinase to peripheral blood cells. Thromb. Haemostasis 58:936-942.

42. Schafer, A. I., and B. Adelman. 1985. Plasmin inhibition of platelet function and arachidonic acid metabolism. J. Clin. Invest. 75:456-461. 